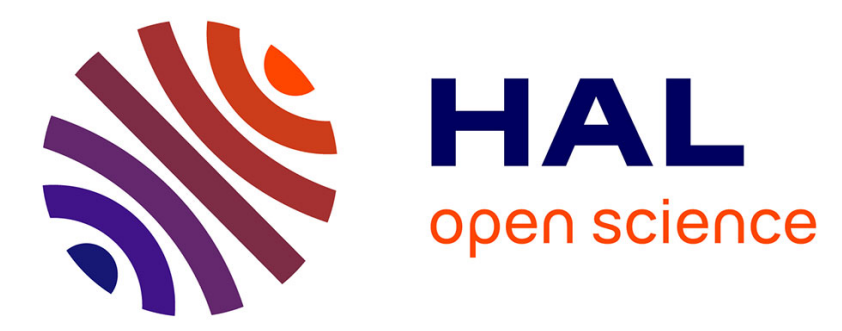

\title{
Multi-scale analysis of the impact of polylactide morphology on gas barrier properties
}

Samira Fernandes Nassar, Alain Guinault, Nicolas Delpouve, Véronique Divry, Violette Ducruet, Cyrille Sollogoub, Sandra Domenek

\section{- To cite this version:}

Samira Fernandes Nassar, Alain Guinault, Nicolas Delpouve, Véronique Divry, Violette Ducruet, et al. Multi-scale analysis of the impact of polylactide morphology on gas barrier properties. Polymer, 2017, 108, pp.163-172. 10.1016/j.polymer.2016.11.047 . hal-01483827

\section{HAL Id: hal-01483827 \\ https://hal.science/hal-01483827}

Submitted on 6 Mar 2017

HAL is a multi-disciplinary open access archive for the deposit and dissemination of scientific research documents, whether they are published or not. The documents may come from teaching and research institutions in France or abroad, or from public or private research centers.
L'archive ouverte pluridisciplinaire HAL, est destinée au dépôt et à la diffusion de documents scientifiques de niveau recherche, publiés ou non, émanant des établissements d'enseignement et de recherche français ou étrangers, des laboratoires publics ou privés. 


\title{
Multi-scale analysis of the impact of polylactide morphology on gas barrier properties
}

\author{
Samira Fernandes Nassar ${ }^{a}$, Alain Guinault ${ }^{b}$, Nicolas Delpouve ${ }^{c}$, Véronique Divry ${ }^{a}$, \\ Violette Ducruet ${ }^{\mathrm{a}}$, Cyrille Sollogoub ${ }^{\mathrm{b}}$, Sandra Domenek ${ }^{\mathrm{a}, \text { * }}$ \\ a UMR Ingénierie Procédés Aliments, AgroParisTech, INRA, Université Paris-Saclay, 1 Avenue des Olympiades, F-91300, Massy, France \\ b PIMM, UMR 8006, Arts et Métiers ParisTech, CNRS, CNAM, 151 Bd de l'Hôpital, F-75013, Paris Cedex, France \\ ${ }^{\mathrm{c}}$ Normandie Univ, UNIROUEN, LECAP, 76000, Rouen, France
}

\section{A R T I C L E I N F O}

\section{Article history:}

Received 13 September 2016

Received in revised form

19 November 2016

Accepted 21 November 2016

Available online 23 November 2016

\section{Keywords:}

PLA

poly(lactic acid)

Crystallization

Amorphous phase

Permeability

Rigid amorphous fraction

Cooperative rearranging region

PLA polymorphism

\section{A B S T R A C T}

Semicrystalline polylactide (PLA) films with controlled morphology were produced by thermal crystallization to optimize the oxygen barrier properties. The crystalline morphology of PLA at the scales of the lamella and the spherulite was investigated and the mobile amorphous phase dynamics were studied. The crystalline morphology had a negligible impact on the oxygen diffusion coefficient. The occurrence of a rigid amorphous fraction (RAF) in the amorphous phase due to its insufficient decoupling from the crystalline phase provided an accelerated pathway for diffusion, though. As a conclusion, for reaching optimal barrier properties, semicrystalline PLA should be pre-nucleated and rapidly crystallized from the glass in the $\alpha$-polymorph in the aim to reach a high crystallinity degree and decoupling of the amorphous and the crystalline phase. These recommendations can benefit to industry for the optimization of PLA annealing treatments.

\section{Introduction}

Poly (lactide), PLA, is today one of the most produced bioplastics. Although there is a growing interest for the use of PLA in durable applications (textile, automotive, printing), rigid and flexible packaging is still its major use. In particular, in short-lived packaging applications, the biodegradable and biobased character of PLA is of environmental advantage. The low gas barrier properties of PLA are, however, a major hurdle to broaden the applications spectrum in this field. For example, PLA is today suitable to pack fresh fruits and vegetables, cheeses or oil containing food but not for contents with long shelf-life, such as infant foods or prepared meals. For that, the oxygen permeability of PLA needs to be decreased by one order of magnitude in the aim of approaching the one of poly (ethylene terephthalate), PET [1,2].

PLA is a semicrystalline polymer, and there has been and is a great research effort for increasing its crystallization kinetics and

\footnotetext{
* Corresponding author.

E-mail address: sandra.domenek@agroparistech.fr (S. Domenek).
}

tailoring its crystallization to specific applications [3]. Crystallization is a means for increasing the gas barrier properties as it acts theoretically on both components of the permeability. Crystallites are excluded volume for the permeants, they bring thus tortuosity to their pathway, which decreases the diffusion coefficient. Furthermore, penetrants cannot sorb into crystalline structures, which decreases the solubility coefficient [4]. From an applied point of view, property improvement by crystallization is advantageous for applications such as packaging, as the process technology is already mastered and it does not need sophisticated addition of processing aids.

However, a number of results in the literature show that the structure/function relationship between PLA morphology and gas barrier properties is not completely understood yet [5-9]. In some cases, constancy or even an increase in the oxygen permeability with an increasing crystallinity degree of PLA was found [6,9]. A similar result was also observed in the case of the water vapour permeability of crystallized PLA [10,11]. Kanehashi et al. [12] did an impressive review on approximately 300 studies concerning the relationship between gas permeability and crystallinity of various polymers. They demonstrated, that the diffusion coefficient and the 
permeability were constant at low degrees of crystallization, regardless the polymer. Drieskens et al. [13] and Guinault et al. [14] analysed more precisely the change of the oxygen barrier properties upon the crystallization of PLA. Both authors showed the decrease of the PLA oxygen permeability at high crystallinity degrees (approximately $>30 \%$ ). However, there was as difference in behaviour occasioned by the crystalline polymorph of PLA [14]. In case of crystallization in $\alpha^{\prime}$-form (also named $\delta$-form by some authors), which is a structurally less ordered crystalline form of PLA [15] obtained at crystallization temperatures lower than $100{ }^{\circ} \mathrm{C}$ $[16,17]$, no reduction of the gas permeability was obtained, even if the crystallization was carried out up to the maximum crystallinity degree [14]. When the PLA crystallization was carried out at high temperatures $\left(>100{ }^{\circ} \mathrm{C}\right.$ ) to obtain the $\alpha$-polymorph, the oxygen permeability could be decreased by a factor of approximately 4 $[13,14]$. Much better results were obtained, when the crystalline morphology was designed by arrangements of parallel lamellae perpendicular to the permeation direction. This was achieved with "shish-kebab like" structures by Bai et al. [18].

The transport properties in PLA are also strongly linked to the nature of the amorphous phase, which includes its content, its dynamics, and its degree of coupling with the crystalline phase. The morphology of semicrystalline PLA and its amorphous phase dynamics were described with the help of the three-phase model, including the crystalline phase, and two fractions of the amorphous phase, i.e. the mobile amorphous fraction (MAF) and the rigid amorphous fraction (RAF) [19-22]. The RAF is the intermediate phase connecting the crystalline phase to the mobile amorphous fraction (MAF) [23]. The RAF constitutes a dedensified amorphous phase [24] because of geometrical constraints preventing structure relaxation. Guinault et al. [14] showed that the formation of RAF was favoured when PLA was crystallized from the glassy state in $\alpha^{\prime}$ form. They suggested that it constituted therefore an accelerated pathway for transport of penetrants around crystalline lamellae, counteracting the tortuosity increase occasioned by the same lamellae. Delpouve et al. [25] worked on the cooperativity length and the fragility index of semicrystalline bi-axially stretched and post-stretching annealed PLA samples. They showed that the amorphous phase of the annealed samples had accelerated segmental motions, which would be beneficial for the gas permeability and not for the barrier properties.

The objective of this study is to optimize the crystallization conditions of PLA to get better oxygen barrier properties by investigating the impact of the crystalline morphology, structure and space filling as well as the amorphous phase dynamics. For that, a set of samples with different size of spherulites and PLA polymorphs was prepared. The experimental conditions were chosen to either favour the formation of RAF or not. The amorphous phase dynamics were analysed by modulated-temperature differential scanning calorimetry (MT-DSC) and the crystalline structure by X-ray diffraction, optical and electron microscopy. These data were linked to the oxygen permeability parameters.

\section{Material and methods}

\subsection{Sample preparation}

Poly (lactide) 4042D was purchased from NatureWorks LLC (USA) and has a percentage of D-lactide acid units of $4.3 \%$. The PLA pellets were dried under low pressure $\left(10^{4} \mathrm{~Pa}\right)$ for $4 \mathrm{~h}$ at $90{ }^{\circ} \mathrm{C}$ and subsequently extruded by single screw extrusion with a $30 \mathrm{~mm}$ diameter extruder (with a $33 \mathrm{~L} / \mathrm{D}$ (length on diameter) barrel) and a three sections screw without mixing elements. The extruder screw speed was set to $40 \mathrm{rpm}$. The temperature profile of the barrel for the six zones, as presented in Fig. 1, was 180-180-180-185-190-
$190{ }^{\circ} \mathrm{C}$. The temperature of the mixer device (4 Sulzer SMX ${ }^{\circledR}$ ) and the die was $200{ }^{\circ} \mathrm{C}$. A flat die of $200 \mathrm{~mm}$ width and a chill roll equipment were used to manufacture films of approximately $300 \mu \mathrm{m}$ thickness. The roll temperature was fixed at $20^{\circ} \mathrm{C}$ to cool down the films. In order to obtain samples with defined microstructure, two procedures of annealing were performed on PLA films. For annealing from the glassy state, the films were sandwiched between two Teflon sheets and two stainless steel plates and placed directly in an oven at the temperature of annealing $\left(85{ }^{\circ} \mathrm{C}\right.$ or $\left.130{ }^{\circ} \mathrm{C}\right)$. They were pressed by a weight of $10 \mathrm{~kg}$. For annealing from the melted state, the samples were sandwiched between two Teflon sheets and two stainless steel plates then pressed above the fusion temperature $\left(210{ }^{\circ} \mathrm{C}\right.$ during $\left.10 \mathrm{~min}\right)$ at $5 \times 10^{6} \mathrm{~Pa}$ with the help of a thermal press (Darragon, France). After that time, they were taken out quickly and placed in the oven at the temperature of annealing $\left(85^{\circ} \mathrm{C}\right.$ or $130{ }^{\circ} \mathrm{C}$ ), where they were maintained under a weight of $10 \mathrm{~kg}$. The procedure of isothermal crystallization in the oven was chosen because of the constraint to produce large samples (diameter $=10 \mathrm{~cm}$ ) compatible with permeability measurements. After the process, the sandwich was quickly opened and the films were quenched to room temperature at a cold surface. Then they were stored at room temperature. Samples studied in this work were chosen by visual inspection, i.e. only samples that appeared to be homogeneous across the surface were selected and analysed.

Sample codes contain the way of crystallizing from the melt, coded with "M", and from the glass, coded with "G", followed by a number denoting the annealing temperature, then a number indicating the duration of annealing and a number giving the crystallinity degree. For example "G85_1200_39" means crystallized from the glass at $85{ }^{\circ} \mathrm{C}$ during $1200 \mathrm{~min}$ and having a crystallinity degree of $39 \%$.

\subsection{Sample characterization}

To choose representative samples for investigating the barrier properties in relation with the microstructure, the crystallization kinetics in the oven were recorded for each annealing treatment. The thermal features of the samples were analysed by means of differential scanning calorimetry in a Q100 DSC (TA Instruments) apparatus, equipped with an intracooler. The temperature calibration was performed with the help of indium and zinc standards and the calibration of the heat capacity was done with the help of a sapphire standard. The purge gas flow was $50 \mathrm{~mL} \mathrm{~min}^{-1} \mathrm{~N}_{2}$. The samples (5-8 $\mathrm{mg}$, loaded in aluminium Tzero crucibles) were heated at a constant heating rate of $10^{\circ} \mathrm{C} \cdot \mathrm{min}^{-1}$ from 20 to $200^{\circ} \mathrm{C}$.

The crystalline morphology of the films was investigated with microscopy techniques. The samples were observed by using an optical transmission microscope (Nachet, France) under polarized light. The samples were prepared using a microtome (Leica, France) to yield thin samples of 5-10 $\mu \mathrm{m}$ thickness. Enzymatic digestion was carried out on samples by immersion in a solution of Tris (tris hydroxymethyl aminomethane, $0.05 \mathrm{M}$ ) with $\mathrm{pH} 8$ containing $800 \mu \mathrm{m} \mathrm{mL}^{-1}$ of proteinase $\mathrm{K}$ during $5 \mathrm{~h}$ at $37^{\circ} \mathrm{C}$. Then, the samples were coated with a thin gold film and observed in a scanning electron microscopy (EVO MA 10 Zeiss with tungsten electrode).

The crystalline structure of the films samples was investigated by wide-angle and small-angle X-ray scattering (WAXS and SAXS) using the SWING beamline of Soleil (St. Aubin, France). The incident beam energy was $12 \mathrm{KeV}(1.03 \AA$ ) and its size was $30 \mu \mathrm{m}$ in height and $300 \mu \mathrm{m}$ in width. The sample-detector distance was $1555 \mathrm{~mm}$ for the SAXS measurements and $555.5 \mathrm{~mm}$ for the WAXS measurements.

The content of each fraction of the amorphous phase and the cooperativity length at the glass transition were investigated by 


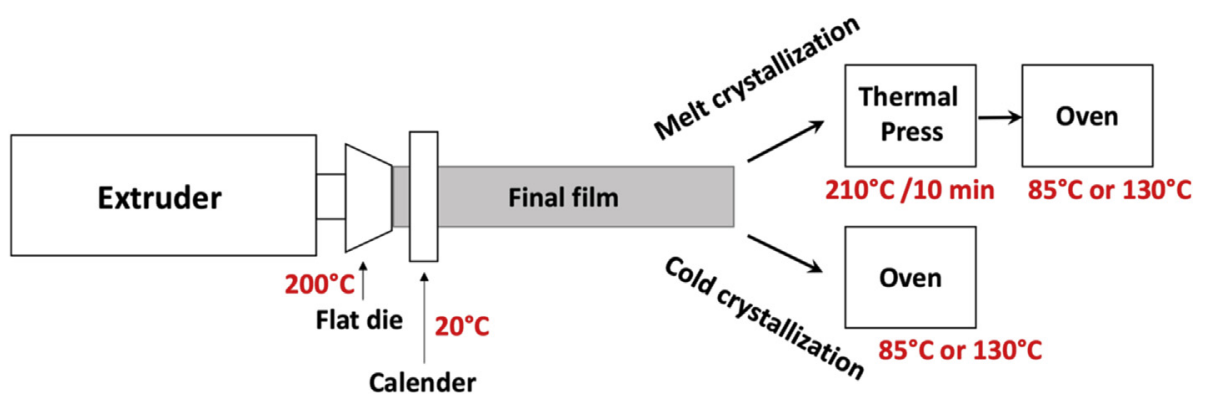

Fig. 1. Schematic representation of the sample preparation process including the extrusion and the annealing procedure.

modulated-temperature differential scanning calorimetry (MTDSC, Q100, TA Instruments) using the heat-only (oscillation amplitude of $0.318{ }^{\circ} \mathrm{C}$, oscillation period of $60 \mathrm{~s}$ and heating rate of $2{ }^{\circ} \mathrm{C} \min ^{-1}$ from $-20{ }^{\circ} \mathrm{C}$ to $200{ }^{\circ} \mathrm{C}$ ) and the heat-cool (oscillation amplitude of $2.5^{\circ} \mathrm{C}$, oscillation period of $100 \mathrm{~s}$ and heating rate of $1{ }^{\circ} \mathrm{C} \mathrm{min}^{-1}$ from $-20{ }^{\circ} \mathrm{C}$ to $70^{\circ} \mathrm{C}$ ) procedure as recommended in Ref. [26]. For the analysis of thermal transitions, a minimum of five modulation steps during the transition is required. In the heat-only mode the instant heating rate never drops below zero. This mode is recommended for the analysis of crystallization and melting, because this analysis is not perturbed by the reversible crystallization. The heat-cool mode consists in heating the sample while modulating the temperature with alternating positive and negative instantaneous heating rates. This mode is adapted for the measurement of the glass transition [27].

The oxygen permeability was measured with a Systech analyser 8001 at $23^{\circ} \mathrm{C}$ and $0 \%$ relative humidity. The oxygen permeability was calculated from the measured oxygen transmission rate (OTR) by multiplying it by the sample thickness (measured with a micrometer on 9 points). For assessing reproducibility, the permeability measurements were carried out on at least two different samples obtained by the same temperature protocol. The measurement variability of the permeability was $\pm 10 \%$. The Diffusion (D) and the Sorption (S) coefficient were calculated with the help of the time-lag method. The time lag $\left(t_{l a g}\right)$ was obtained by calculating the intercept on the abscissa of the cumulated flux curve, and D was found by evaluating

$t_{\text {lag }}=\frac{L^{2}}{6 D}$

where $\mathrm{L}$ is the sample thickness. S was obtained with the help of the general relationship, $P=D \cdot S$, where $\mathrm{P}$ denotes the permeability.

\section{Results and discussion}

\subsection{PLA crystallization kinetics}

In the aim of choosing annealed PLA samples with controlled morphology and structure, the crystallization kinetics under the annealing conditions in the oven were recorded. We recall that the crystallization kinetics, which are shown in Fig. 2, were measured on large samples obtained by annealing between metal plates in an oven. The degree of crystallinity $\left(\mathrm{X}_{\mathrm{c}}\right)$ of the PLA samples was calculated from

$\mathrm{X}_{\mathrm{c}}=\frac{\Delta \mathrm{H}_{\mathrm{f}}-\Delta \mathrm{H}_{\mathrm{cc}}}{\Delta \mathrm{H}_{\mathrm{f}}^{0}}$,

where $\Delta \mathrm{H}_{\mathrm{f}}$ is the enthalpy of fusion or melting after subtraction of the small exothermal event at the beginning of the melting peak,
$\Delta \mathrm{H}_{\mathrm{cc}}$ is the enthalpy of the cold crystallization, and $\Delta \mathrm{H}_{\mathrm{f}}{ }^{\circ}$ is the enthalpy of the melting of the perfect crystal of infinite size, i.e. the totally crystalline polymer $(93.1 \mathrm{~J} / \mathrm{g}$ [28]). Due to the polymorphic nature of PLA leading to a melt recrystallization process and to its complex stereo-chemistry, this value may reasonably be debated [29]. The crystallization kinetics are plotted in Fig. 2. The path of crystallization discriminated the overall crystallization kinetics. The change in the crystallization rate due to the annealing temperatures could not be discriminated in the present experimental set-up. We think that the procedure in the annealing oven involved non isothermal nucleation, because of the time necessary for the oven to adjust and stabilize the temperature (approximately $10 \mathrm{~min}$ ) after opening of the door for putting in the sample. The crystallization rate was faster from the glass than from the melt. When its thermal history was erased by melting, PLA was shown to crystallize slower at low temperatures because of the low amount of energy provided to the system, which delayed the nucleation process [30]. In the present study the samples crystallized from the glass were annealed just after the extrusion process, i.e., in experimental conditions strongly favouring the nucleation. This apparently accelerated the crystallization kinetics, while the samples crystallized from the melt were of course melted before annealing. This processing effect on polymer crystallization kinetics has already been evidenced for isotactic polypropylene [31,32].

\subsection{Crystalline structure and space filling}

Fig. 3 shows the micrographs obtained from polarizing optical microscopy (POM). Looking at the pictures obtained at $85^{\circ} \mathrm{C}$ and at

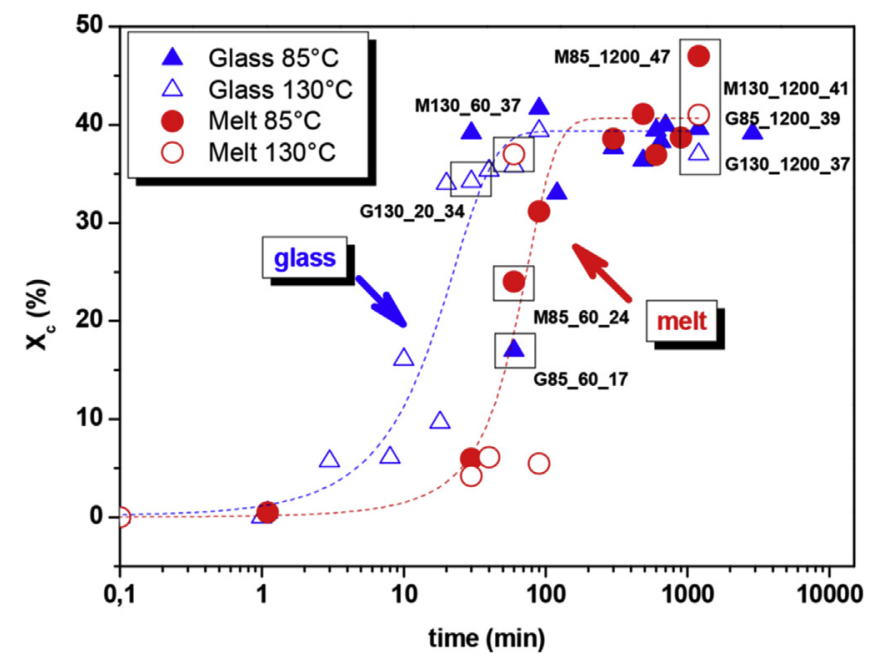

Fig. 2. Crystallization kinetics of PLA in the oven at different temperatures upon annealing from the glassy state and from the melt. 

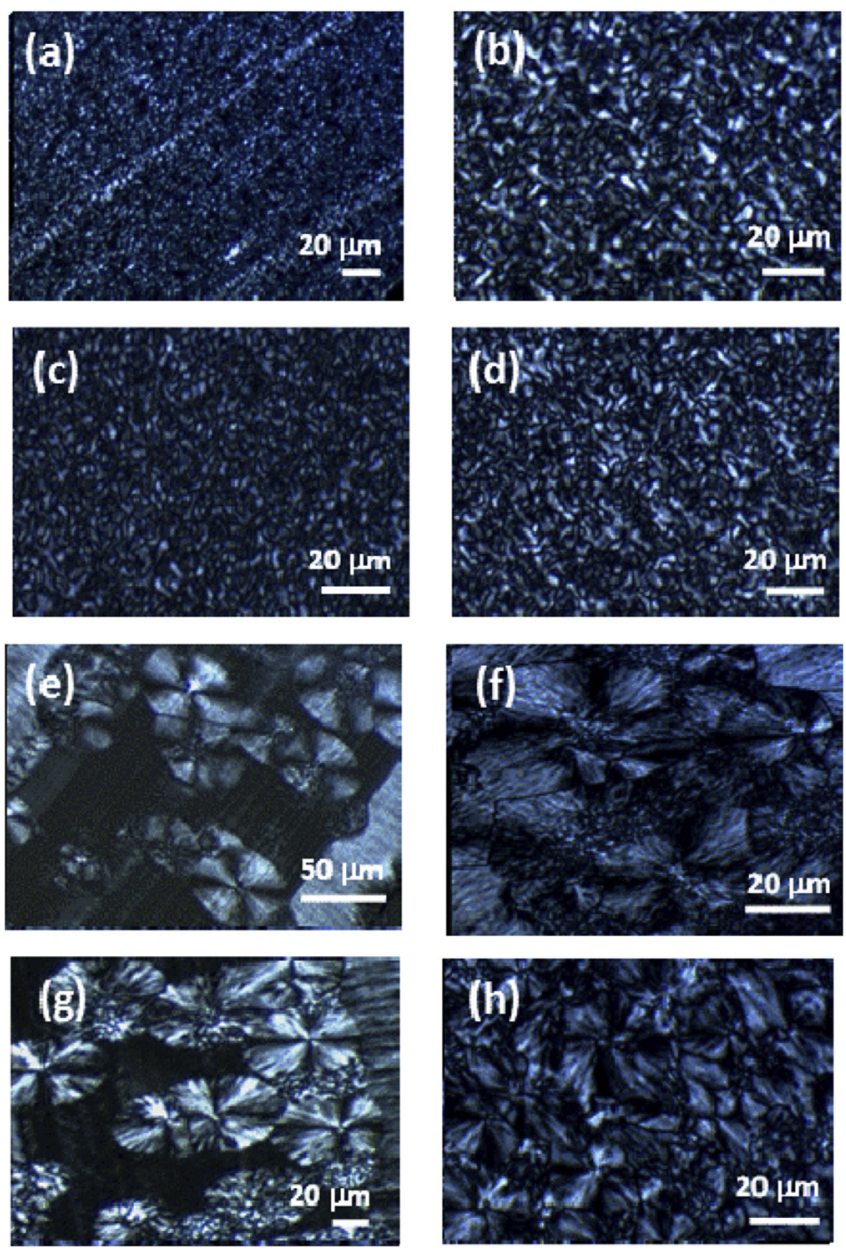

Fig. 3. POM micrographs of PLA samples after crystallization from the glass and from the melt at two different annealing temperatures (a) G85_60_17, (b) G85_1200_39, (c) G130_20_34, (d) G130_1200_37, (e) M85_60_24, (f) M85_1200_47, (g) M130_60_37, (h) M130_1200_41.

$130{ }^{\circ} \mathrm{C}$, one observes that the spherulites obtained from the melt were much larger than the ones obtained from the glass. Their maximum diameter was about $50 \mu \mathrm{m}$ while the spherulites were barely observable after crystallizing from the glass. Pluta and Galeski [33] working in similar conditions reported that spherulites crystallized via cooling from the melt were larger than in those crystallized via heating from the glassy, amorphous state. They attributed this result to the formation of many pre-nuclei during the cooling of the samples to the glassy state that give rise to primary nuclei of crystallization at the annealing temperature. They also observed like several authors that the sizes of the spherulites obtained by crystallization from the melt or the glass increased with the crystallization temperature $[10,14,34,35]$. The observation that our samples presented almost equally large spherulites when crystallized from the melt at 85 and $130{ }^{\circ} \mathrm{C}$ can be explained by assuming non-isothermal crystallization conditions. Under such conditions the radius of the spherulites changes with the temperature at which the precursor nuclei is formed [36]. The maximum nucleation rate of PLA is $120^{\circ} \mathrm{C}$ [37], a temperature which needs to be passed in the annealing procedure at $85{ }^{\circ} \mathrm{C}$ from the melt. The quenching following the melting of PLA in the thermal press to the annealing temperature in the oven was not apparently fast enough to stop the nucleation and crystallization at temperatures higher than $85{ }^{\circ} \mathrm{C}$. Androsch et al. [38,39] showed recently, using fast scanning chip calorimetry, that a cooling rate of $30 \mathrm{~K} \mathrm{~min}^{-1}$ is sufficient to prevent melt crystallization while a cooling rate of $500 \mathrm{~K} \mathrm{~min}^{-1}$ is required to inhibit the formation of nuclei in PLA containing $4 \% \mathrm{D}$-units. This is hardly compatible with processing of large samples, required for the present study.

The space-filling cannot be easily appreciated from the transmission POM pictures because of the absence of the 3D observation. The enzymatic degradation of PLA is strongly sensitive to the crystalline structure [40]. As a result one can get information about the spherulite organization by degrading the amorphous matrix outside the spherulites and trapped inside. Proteinase K works by irreversibly adsorbing on the surface of the PLA film before catalysing the hydrolysis of the ester bond. Tsuji and Miyauchi [41] studied the effect of crystallinity on the enzymatic degradation of PLLA films in the presence of proteinase $K$ and found that the amorphous region outside of the spherulite was predominantly degraded rather than that inside. However, proteinase $\mathrm{K}$ can still access to the intra-spherulite amorphous phase and hydrolyse the spherulitic superstructure. It has been shown that it can even degrade a core of polylactide trapped in a crosslinked shell [42]. The SEM pictures of the sample surfaces after enzymatic degradation are shown in Fig. 4. In agreement with the POM pictures, the crystallization from the melt (Fig. $4 a$ and $b$ ) leads to the formation of bigger spherulites of about $50 \mu \mathrm{m}$ diameter while the crystallization from the glassy state (Fig. $4 \mathrm{c}$ and $\mathrm{d}$ ) generates spherulites of less than $10 \mu \mathrm{m}$ diameter. Due to this size difference the digestion of the intra-spherulite amorphous phase is only visible for samples crystallized from the melt. The degradation of the spherulites crystallized at $85{ }^{\circ} \mathrm{C}$ was more pronounced (Fig. 4a). Furthermore, the spherulites created by crystallization at $85{ }^{\circ} \mathrm{C}$ (Fig. $4 \mathrm{a}$ and c) looked more dispersed, separated from each other, while the spherulites crystallized at $130{ }^{\circ} \mathrm{C}$ (Fig. $4 \mathrm{~b}$ and d) seemed to touch each other. This higher space-filling was particularly obvious on the picture of the G130_20_34 sample (Fig. 4d). After 5 h of treatment, the enzymatic digestion penetrated barely into the sample and no single spherulites could be revealed. The high quantity of small spherulites (observed in Fig. 3c) apparently hindered the access of the enzyme to the amorphous phase of the samples.

\subsection{Crystalline morphology}

The SAXS traces presented in Fig. 5 show that the main diffraction peak of the samples crystallized at $130^{\circ} \mathrm{C}$ was located at smaller angles (smaller q) than that of the samples crystallized at $85{ }^{\circ} \mathrm{C}$. This is in coherence with existing literature [34]. The maximum of the SAXS distribution peak appears as a result of the periodicity in the arrangement of the crystalline and amorphous phases (the stacks of lamellar, amorphous regions). The samples crystallized at $130{ }^{\circ} \mathrm{C}$ exhibited, as expected, a larger average long period $\mathrm{L}_{\mathrm{z}}$ (Table 1 ) and a narrower distribution of the lamellae thicknesses. On the other hand, the samples crystallized at $85{ }^{\circ} \mathrm{C}$ which showed a broader peak shifted towards larger angles. They present thus a more heterogeneous population of lamellar stacks, with a smaller $\mathrm{L}_{z}$ (Table 1 ). $\mathrm{L}_{z}$ did not depend on the crystallization pathway, i.e. crystallization from the glass or the melt.

The WAXS diffractograms are plotted in Fig. 6. The analysis of the reflections enables the determination of the crystalline polymorph of PLA in function of the sample preparation procedure. For easier comparison, all the diffraction were normalized using the strongest (110)/(200) reflection intensity. Di Lorenzo et al. [43] attributed the different peaks in the WAXS patterns of the $\alpha$ - and $\alpha^{\prime}$-forms of PLA. The $\alpha^{\prime}$-form presents small differences in the $2 \theta$ values for the two strongest reflections, (110)/(200) and (203) planes. Based on these reflections, the d-spacings of the lattice planes can be calculated from the $2 \theta$ positions using Bragg's law. Samples crystallized at $130{ }^{\circ} \mathrm{C}$ had a smaller interplanar distance 

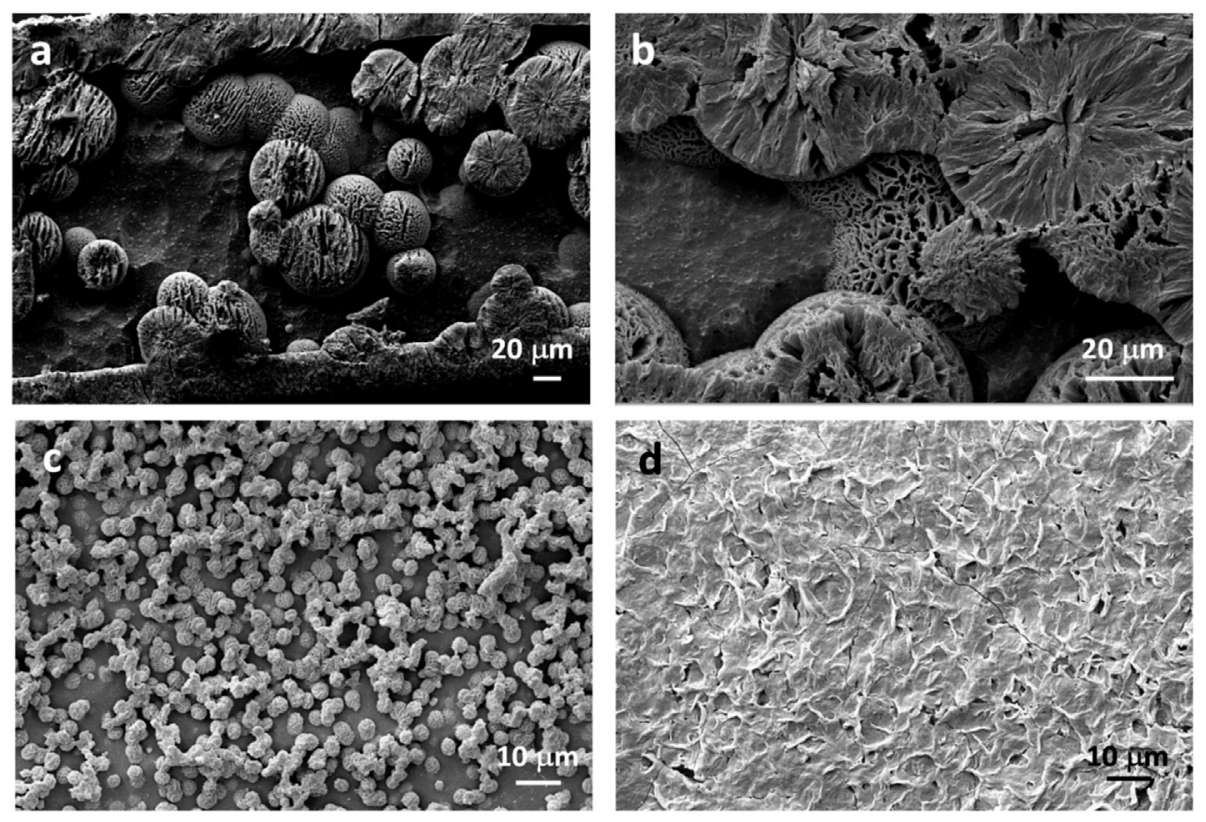

Fig. 4. SEM pictures of PLA annealed from the glass and from the melt after 5 h enzymatic digestion (a) M85_60_24 (b) M130_60_37 (c) G85_60_17 (d) G130_20_34.
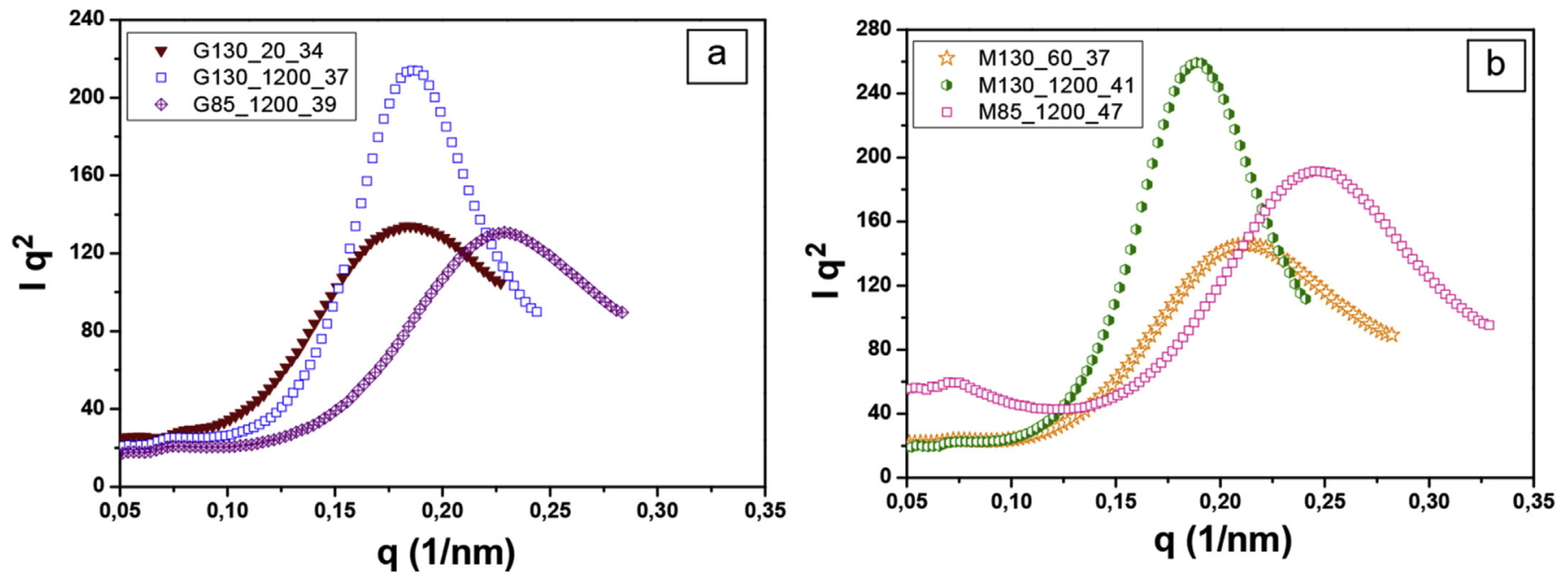

Fig. 5. Lorentz-corrected SAXS profiles for PLA samples crystallized from the (a) glass and (b) melt at $85{ }^{\circ} \mathrm{C}$ and $130{ }^{\circ} \mathrm{C}$.

compared to samples crystallized at $85{ }^{\circ} \mathrm{C}$ (Table 1 ). This showed together with the results obtained from SEM and SAXS measurements that the microstructure generated at $130{ }^{\circ} \mathrm{C}$ was more

Table 1

Long period and d-spacings respectively obtained from SAXS and WAXS analyses.

\begin{tabular}{|c|c|c|c|}
\hline & $\mathrm{L}_{\mathrm{z}}$ & d-sp. $110 / 200$ & d-sp. 203 \\
\hline & $(\mathrm{nm})$ & $(\mathrm{nm})$ & $(\mathrm{nm})$ \\
\hline G85_60_17 & n.d. & 0.5290 & 0.4637 \\
\hline G85_1200_39 & 27.5 & 0.5270 & 0.4615 \\
\hline G130_20_34 & 34 & 0.5255 & 0.4606 \\
\hline G130_1200_37 & 33.3 & 0.5249 & 0.4601 \\
\hline M85_60_24 & n.d. & 0.5274 & 0.4608 \\
\hline M85_1200_47 & 25.6 & 0.5280 & 0.4613 \\
\hline M130_60_37 & 29.9 & 0.5249 & 0.4615 \\
\hline M130_1200_41 & 33.3 & 0.5255 & 0.4599 \\
\hline
\end{tabular}

n.d. non determined. organized. It is worth mentioning that the WAXS spectra did not allow to discriminate the $\alpha^{\prime}$-and the $\alpha$-polymorph as a function of the crystallization temperature. This could be the consequence of the sample annealing procedure which involved non-isothermal nucleation.

\subsection{Structural description of the amorphous phase and its cooperativity at the glass transition}

As for many semi-crystalline polymers, the classic structural representation of PLA separates the amorphous phase into a fraction relaxing at the glass transition, i.e., the mobile amorphous fraction (MAF), and its counterpart, the rigid amorphous fraction (RAF) which devitrifies at higher temperatures [21,43-46]. The RAF existence is due to the length of the polymer molecules that is much higher than the dimensions of the crystalline phase, leading to an incomplete decoupling between the amorphous phase and 

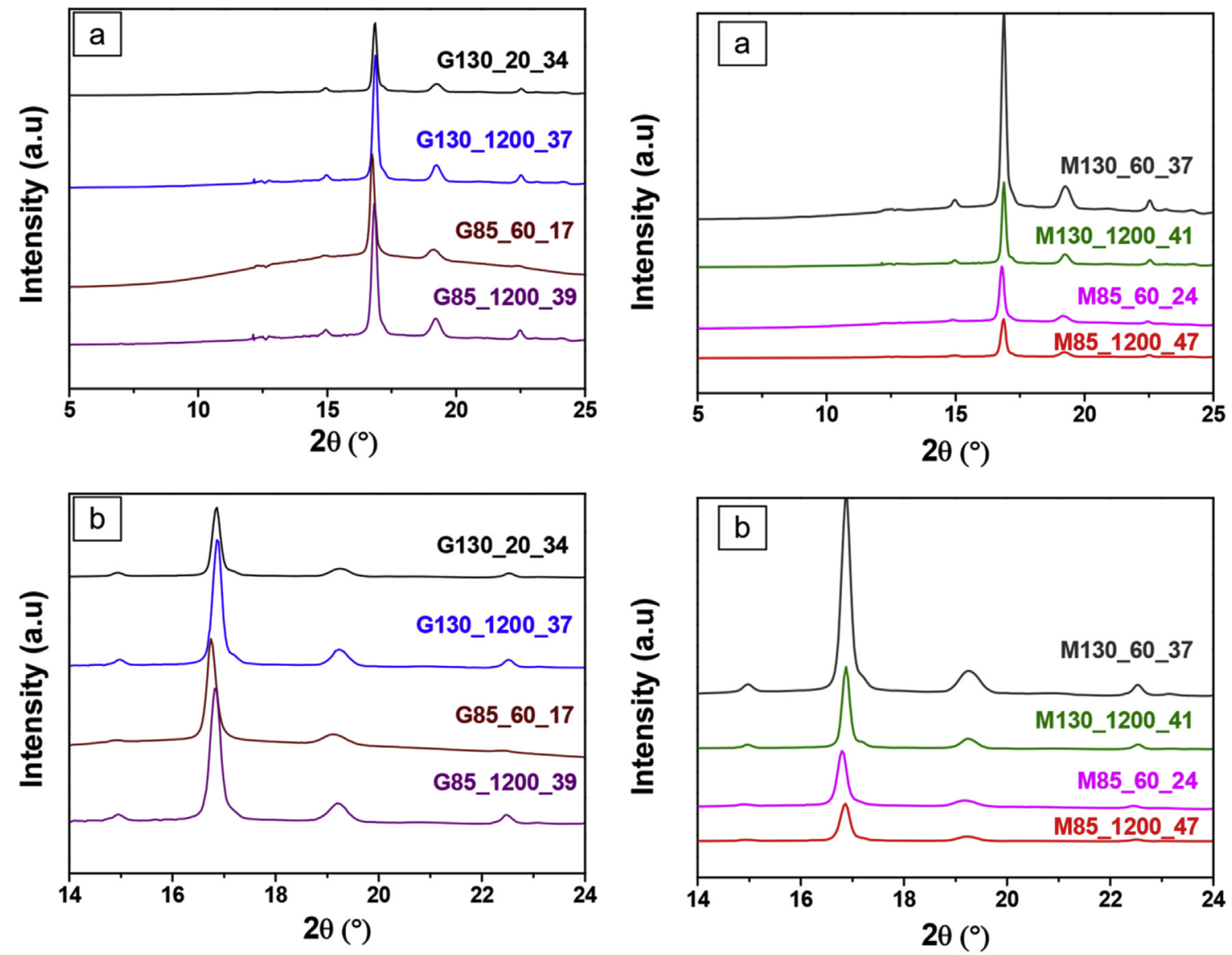

Fig. 6. (a) WAXS patterns and (b) enlarged patterns of PLA samples crystallized from the glassy state and from the melt.

the crystals. The content of RAF in polylactide, $\mathrm{X}_{\mathrm{RA}}$, depends on the conditions of crystallization and can vary from $0 \%$ to $35 \%$ [30]. Although this approach may look simplistic since it limits the description of the amorphous phase to its structure without considering its dynamics, the studies of Guinault et al. [14], Drieskens et al. [13], and Delpouve et al. [11] proposed that an important amount of RAF is prejudicial for the barrier properties of PLA.

The content of the RAF can be calculated after

$X_{c}+X_{M A}+X_{R A}=100 \%$ with $X_{M A}=\frac{\Delta C_{p}}{\Delta C_{p}{ }^{0}}$,

where $\mathrm{X}_{\mathrm{RA}}$ is the content of MAF, $\Delta \mathrm{C}_{\mathrm{p}}$ is the heat capacity change measured at the glass transition and $\Delta C_{\mathrm{P}}^{0}$ the heat capacity change of the fully amorphous sample. The quantitative analysis of the thermal events was done thanks to MT-DSC by separating the events related to the variations of the heat capacity, which appear in the reversing heat flow, from the kinetic events, which appear in the non-reversing heat flow. An example of this protocol is given in Fig. 7a. The difference between the enthalpy of cold-crystallization and the enthalpy of melting for the determination of the degree of crystallinity was double checked using, on the one hand, the average heat flow signal as usually performed in classical DSC, and, on the other hand, the reversing and the non-reversing heat flow signals from the MT-DSC. At the same time, the glass transition temperature and $\Delta C_{p}$ was systematically measured from the reversing heat flow (Fig. 7b) with $\Delta C_{P}^{0}$ determined to be $0.52 \mathrm{~J}$ (g.
$\mathrm{K})^{-1}$. The results are presented in Table 2 .

An increasing time of annealing increased the degree of crystallinity. Only two materials did not reach their maximum degree of crystallinity according to their values of enthalpy of coldcrystallization that differ from zero (Table 2). Among the others and in concordance with Fig. 2, the crystallization from the melt led to higher $\Delta \mathrm{H}_{\mathrm{f}}$ and consequently to higher $\mathrm{X}_{\mathrm{C}}$ after prolonging annealing although the variations are small. The quantity of measured $\mathrm{X}_{\mathrm{MA}}$ at long annealing times seemed to depend on the annealing temperature. It was about $9 \%$ lower when crystallizing PLA at $85^{\circ} \mathrm{C}$ compared to $130^{\circ} \mathrm{C}$. One could interpret in a first time this result as evidence that the MAF underwent a stronger confinement. However, it may be hasty to do such a comparison since it would consider that the mobility landscape of the MAF was independent from the temperature of annealing. On the other hand the values of $\mathrm{X}_{\mathrm{RA}}$ clearly evidenced a higher coupling between crystals and amorphous phase when crystallizing at $85{ }^{\circ} \mathrm{C}$. This means that the repartition between RAF and MAF depended on the temperature and time of annealing, even if nucleation pre-existed in the material. A high temperature of annealing allowed thus both perfecting the crystalline structure (more homogenous structure shown by XRD in Figs. 5 and 6) and better decoupling amorphous and crystal phases.

For equivalent annealing temperatures, $\mathrm{T}_{\mathrm{g}}$ was slightly higher, about $2{ }^{\circ} \mathrm{C}$, when crystallizing from glassy state. For an equivalent path of crystallization, $\mathrm{T}_{\mathrm{g}}$ was higher when crystallizing at $85^{\circ} \mathrm{C}$. The shift of $\mathrm{T}_{\mathrm{g}}$ towards higher values upon crystallization is characteristic of the constrained amorphous phase between crystalline lamellae, which relaxes only at higher temperatures $[19,20]$. 

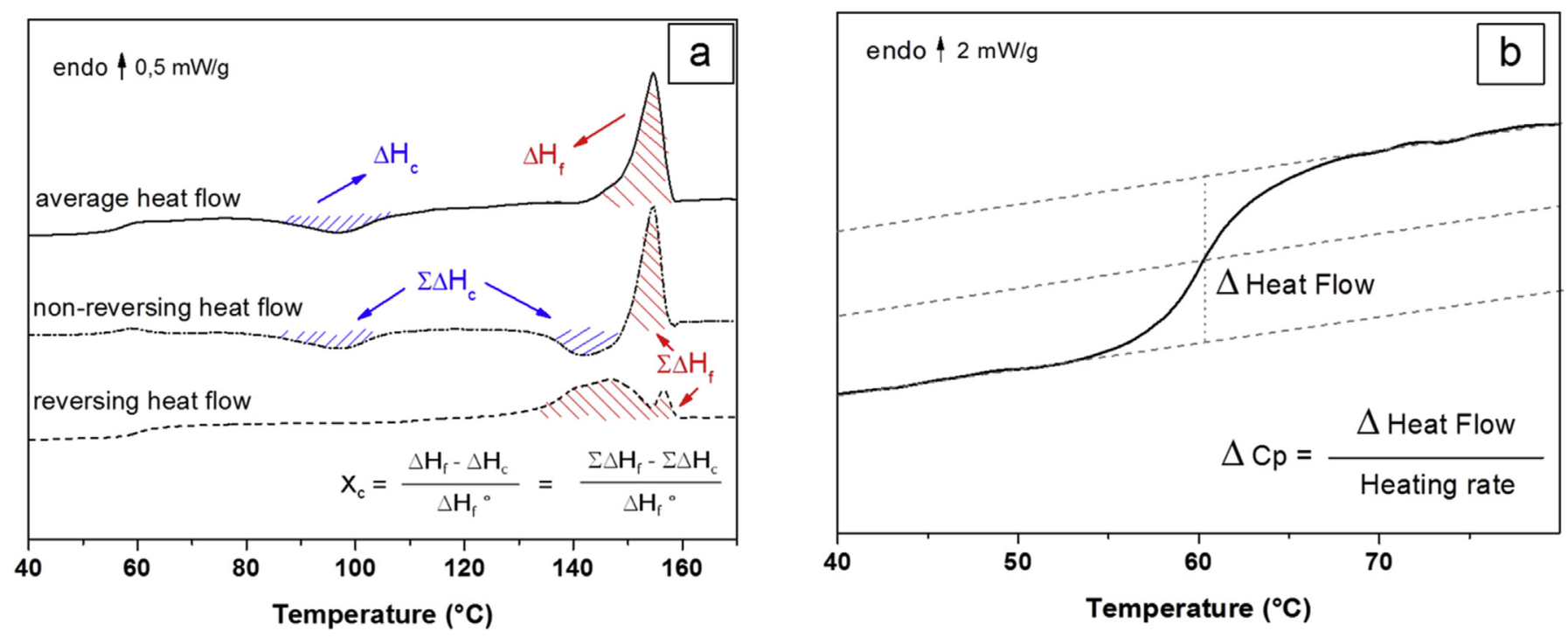

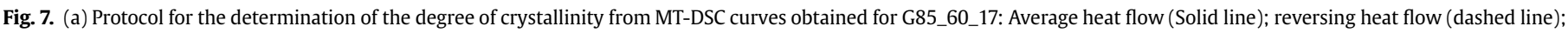
and non-reversing heat flow (dotted line) versus temperature; (b) reversing heat flow in the glass transition domain.

Among crystallized samples, it has been shown that $\mathrm{T}_{\mathrm{g}}$ also shifts to higher temperatures when the crystallization conditions did not allow a correct decoupling between the amorphous and the crystalline phase [26]. The RAF was more important when samples were crystallized at a lower temperature. This seems consistent with the results of Guinault et al. [14] who described that important formation of RAF was linked to imperfect crystallization of PLA. It is assumed that at low crystallization temperature, typically $85^{\circ} \mathrm{C}$, the lack of chain mobility hinders the reorganization of polymeric segments in crystals and induces many chain segments subjected to geometrical restrictions in the amorphous phase [47]. Most interestingly, we show here that this observation could be extended to imperfect conditions of crystallization in general, including the predominance of germination over growth that led to the formation of low-size spherulites. In particular, G85_1200_39 sample had the highest RAF degree (21\%, Table 2 ).

To understand how the mobile amorphous phase was itself impacted by the presence of RAF, the size of cooperative rearranging region (CRR) $\xi_{T \alpha}$ was calculated. A CRR is defined as the smallest amorphous domain where a conformational rearrangement may occur without causing rearrangements in the surroundings [48]. This approach probes the amorphous phase dynamics by providing a picture of the relaxation time at the glass transition which is directly observable through calorimetric measurements [49], and more precisely from the analysis of the in- phase component $\mathrm{C}^{\prime}$ and the out-of-phase component $\mathrm{C}^{\prime \prime}$ of the complex heat capacity measured by MT-DSC. An example of these two signals is given in Fig. 8. According to this approach [50], the cooperativity volume $\xi_{\text {T } \alpha}^{3}$ of a CRR at the dynamic glass transition temperature $\mathrm{T}_{\alpha}$ can be estimated from the following equation:

$\xi_{T \alpha}^{3}=\frac{\left(1 / C_{p}\right)_{\text {Glasss }}{ }_{T \alpha}-\left(1 / C_{p}\right)_{\text {Liquid }} T \alpha}{\rho(\delta T)^{2}} k_{B} T_{\alpha}^{2}$,

with $\mathrm{k}_{\mathrm{B}}$ the Boltzmann constant, $\delta \mathrm{T}$ the average temperature fluctuation related to the dynamic glass transition of a CRR which is determined from the Gaussian fit of C" [49], $\rho$ the density, and $C_{p}$ the heat capacity at constant pressure. The values of $C_{p}$ glass $T \alpha$ and $\mathrm{C}_{\mathrm{p} \text { liquid } \mathrm{T} \alpha}$. were obtained by prolonging the glass and liquid lines to dynamic glass transition temperature after normalization to the MAF content [18]. When the crystallization is not performed to its maximum extent, the MAF splits into intra- and inter-spherulitic amorphous regions and calorimetric measurements can show two separate signatures within the glass transition temperature range [20]. To overcome the issues related to such a complex molecular mobility landscape, the investigation of the CRR size was limited to the samples having reached their maximum degree of crystallinity. The results are presented in Table 3. As expected all

Table 2

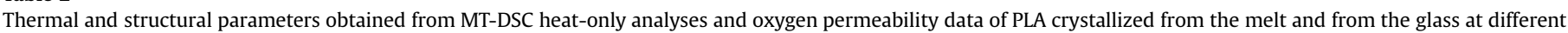
annealing temperatures.

\begin{tabular}{|c|c|c|c|c|c|c|c|c|c|c|}
\hline & $\mathrm{T}_{\mathrm{g}}$ & $\Delta \mathrm{C}_{\mathrm{p}}$ & $\Delta \mathrm{H}_{\mathrm{c}}$ & $\Delta \mathrm{H}_{\mathrm{f}}$ & $\mathrm{X}_{\mathrm{c}}$ & $\mathrm{X}_{\mathrm{ma}}$ & $\mathrm{X}_{\mathrm{ra}}$ & P. $10^{18}$ & D. $10^{12}$ & S. $10^{6}$ \\
\hline & $\left({ }^{\circ} \mathrm{C}\right)$ & $\left(\mathrm{Jg}^{-1} \mathrm{~K}^{-1}\right)$ & $\left(\mathrm{Jg}^{-1}\right)$ & $\left(\mathrm{Jg}^{-1}\right)$ & $(\%)$ & $(\%)$ & $(\%)$ & $\left(\mathrm{m}^{3} \cdot \mathrm{m} \cdot \mathrm{m}^{-2} \cdot \mathrm{s}^{-1} \cdot \mathrm{Pa}^{-1}\right)$ & $\left(\mathrm{m}^{2} \cdot \mathrm{s}^{-1}\right)$ & $\left(\mathrm{m}^{3} \cdot \mathrm{m}^{-3} \cdot \mathrm{Pa}^{-1}\right)$ \\
\hline Amorphous & 58.0 & 0.52 & - & - & 0 & - & - & 2.30 & 1.8 & 1.3 \\
\hline G85_60_17 & 57.2 & 0.39 & 11 & 27 & 17 & 75 & 8 & 1.73 & 1.5 & 1.1 \\
\hline G85_1200_39 & 56.1 & 0.21 & 0 & 36 & 39 & 40 & 21 & 1.33 & 1.7 & 0.8 \\
\hline G130_20_34 & 56.1 & 0.31 & 0 & 32 & 34 & 60 & 6 & 0.58 & 0.7 & 0.8 \\
\hline G130_1200_37 & 53.5 & 0.26 & 0 & 34 & 37 & 50 & 13 & 0.93 & 1.2 & 0.8 \\
\hline M85_60_24 & 56.9 & 0.38 & 10 & 32 & 24 & 73 & 3 & 1.29 & 1.1 & 1.2 \\
\hline M85_1200_47 & 54.8 & 0.20 & 0 & 43 & 47 & 38 & 15 & 0.88 & 1.2 & 0.8 \\
\hline M130_60_37 & 56.3 & 0.30 & 0 & 34 & 37 & 58 & 5 & 0.87 & 0.9 & 0.9 \\
\hline M130_1200_41 & 53.2 & 0.24 & 0 & 38 & 41 & 46 & 13 & 0.77 & 1.1 & 0.7 \\
\hline
\end{tabular}




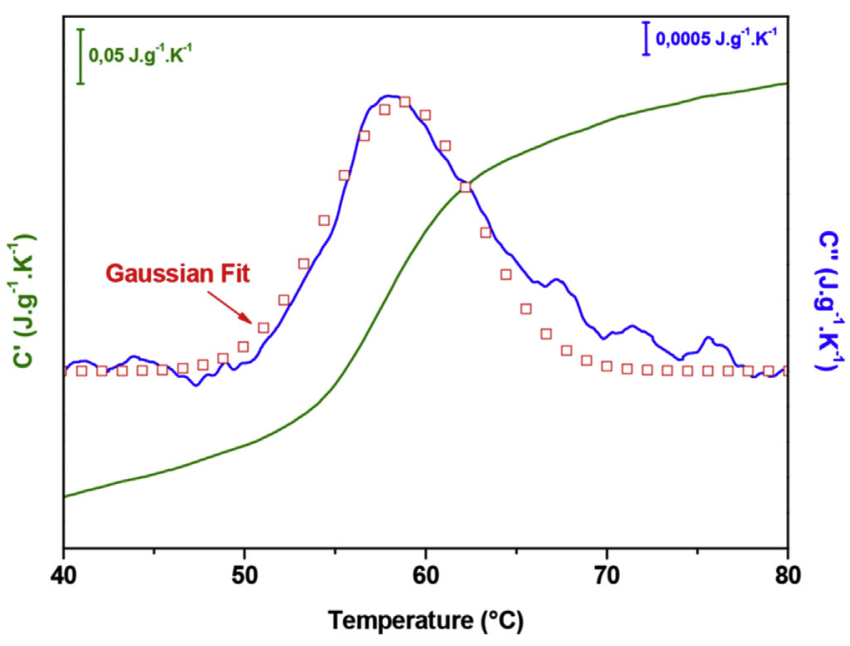

Fig. 8. In-phase component C' (green line) and out-of-phase component C"' (blue line) from heat-cool mode in MT-DSC obtained for the G130_20_34. The red squares correspond to the adjusted Gaussian fit of C". (For interpretation of the references to colour in this figure legend, the reader is referred to the web version of this article.)

Table 3

Amorphous phase relaxation parameters obtained from MT-DSC heat-cool analyses.

\begin{tabular}{|c|c|c|c|c|c|}
\hline & $\mathrm{T} \alpha$ & $\mathrm{Cp}$ glass $\mathrm{T} \alpha$ & $\mathrm{Cp}$ liquid $\mathrm{T} \alpha$ & $\delta \mathrm{T}$ & CRR size \\
\hline & $\left({ }^{\circ} \mathrm{C}\right)$ & $\left(\mathrm{Jg}^{-1} \mathrm{~K}^{-1}\right)$ & $\left(\mathrm{Jg}^{-1} \mathrm{~K}^{-1}\right)$ & $\left({ }^{\circ} \mathrm{C}\right)$ & $(\mathrm{nm})$ \\
\hline Amorphous [29] & 60.5 & 1.46 & 1.97 & 3 & 3.0 \\
\hline G85_1200_39 & 54.4 & 1.45 & 1.95 & 4.7 & 2.1 \\
\hline G130_20_34 & 58.4 & 1.25 & 1.85 & 4 & 2.5 \\
\hline G130_1200_37 & 53.3 & 1.22 & 1.76 & 4.1 & 2.4 \\
\hline M85_1200_47 & 56.5 & 1.20 & 1.70 & 5.5 & 1.9 \\
\hline M130_60_37 & 57.6 & 1.20 & 1.75 & 3.4 & 2.8 \\
\hline M130_1200_41 & 52.7 & 1.25 & 1.75 & 3.9 & 2.4 \\
\hline
\end{tabular}

materials exhibited a lower CRR size compared to an amorphous sample which is $3.0 \mathrm{~nm}$ [30]. Investigating the semicrystalline materials, the variations of $T_{\alpha}$ followed the variations of $T_{g}$ as expected. While the values of $C_{p}$ were barely affected by the thermal treatments, $\delta \mathrm{T}$ was clearly higher for the samples crystallized at $85^{\circ} \mathrm{C}$ which resulted in a lower size of CRR [26]. This behaviour can also be seen when comparing the amount of rigid amorphous fraction and CRR. At $85{ }^{\circ} \mathrm{C}$ the RAF was higher and influenced the CRR size. The impact of crystallization processes on CRR size was shown in previous articles [19,25,30,51-53] evidencing the role of the geometric confinement induced by the crystals and the incomplete decoupling between the amorphous and crystalline phases. Obviously the dynamics of the amorphous phase, including the processes of vitrification and relaxation strongly differed when varying the temperature of annealing.

\subsection{Oxygen permeability study}

Table 2 reports the oxygen permeability of the different samples. The barrier properties of PLA were globally improved after the crystallization, and this effect was higher at $\mathrm{T}_{\mathrm{C}}=130^{\circ} \mathrm{C}$ no matter if the crystallization was carried out from glass or from the melt. At the annealing temperature of $85{ }^{\circ} \mathrm{C}$, the crystallization from the melt led to higher barrier properties. The excluded volume hypothesis provides an explanation of the relationship between the crystallinity degree and barrier properties. Crystalline zones are presumed to be excluded volumes through which molecules cannot diffuse and in which they cannot sorb [4]. This is in contrast to the amorphous zones where diffusion and sorption is possible. The crystallites force a more tortuous diffusive pathway of permeants, which, macroscopically, decreases the diffusion coefficient. In addition, crystallites decrease the available volume for permeant sorption, which decreases the overall solubility coefficient of the material.

Two groups of samples could be distinguished in the oxygen permeability data presented in Table 2: the first one was composed of samples obtained with a short crystallization time (example M85_60_24 and G85_60_17). In that case the space filling of the spherulites was not complete (see also Fig. 3 a, e and Fig. 4 a, c), which led to a relatively low gain in the oxygen barrier properties. This gain was driven by the decrease of the diffusion coefficient due to the tortuosity effect induced by the presence of the crystallites. The impact of the crystallinity degree on the oxygen solubility coefficient was smaller than the measurement variability.

The second group was composed of samples, which were crystallized for a long time (1200 min, Fig. 3 b, d, f, h), where complete space filling was reached. In that case, the quantity of RAF guided the results of permeability, while the size and structure of the crystallites had a negligible influence on the barrier properties. This

Table 4

Summary of morphological and structural characteristics of PLA in relation to the thermal treatment and improvement of oxygen barrier properties.

\begin{tabular}{|c|c|c|c|}
\hline & & $\mathrm{T}($ crystallization $)=85^{\circ} \mathrm{C}$ & $\mathrm{T}($ crystallization $)=130{ }^{\circ} \mathrm{C}$ \\
\hline \multirow[t]{6}{*}{$\begin{array}{l}\text { Crystallization from } \\
\text { the glass }\end{array}$} & $\begin{array}{l}\text { Spherulite } \\
\text { morphology }\end{array}$ & - Small spherulites due to preponderant nucleation & - Small spherulites due to preponderant nucleation \\
\hline & Crystalline & - Disordered small crystallites & - Organized phase of crystallites \\
\hline & morphology & - More heterogeneous lamellar stacks & - Less heterogeneous lamellar stacks \\
\hline & $\begin{array}{l}\text { Amorphous phase } \\
\text { dynamics }\end{array}$ & - Low intermolecular interactions in the MAF (small CRR) & $\begin{array}{l}\text { - Average intermolecular interactions in the MAF } \\
\text { (intermediate CRR) }\end{array}$ \\
\hline & & $\begin{array}{l}\text { - High coupling between amorphous and crystalline phase } \\
\text { (high RAF content) }\end{array}$ & $\begin{array}{l}\text { - Low coupling between amorphous and crystalline phase } \\
\text { (low RAF content) }\end{array}$ \\
\hline & $\begin{array}{l}\text { Gain in barrier } \\
\text { properties }\end{array}$ & Low & Best \\
\hline \multirow[t]{6}{*}{$\begin{array}{l}\text { Crystallization from } \\
\text { the melt }\end{array}$} & $\begin{array}{l}\text { Spherulite } \\
\text { morphology }\end{array}$ & $\begin{array}{l}\text { - Big spherulites due to coexistence of germination and } \\
\text { growth }\end{array}$ & $\begin{array}{l}\text { - Big spherulites due to coexistence of germination and } \\
\text { growth }\end{array}$ \\
\hline & Crystalline & - Disordered small crystallites & - Organized phase of crystallites \\
\hline & morphology & - More heterogeneous lamellar stacks & - Less heterogeneous lamellar stacks \\
\hline & $\begin{array}{l}\text { Amorphous phase } \\
\text { dynamics }\end{array}$ & - Low intermolecular interactions in the MAF (small CRR) & $\begin{array}{l}\text { - Average intermolecular interactions in the MAF } \\
\text { (intermediate CRR) }\end{array}$ \\
\hline & & $\begin{array}{l}\text { - Average coupling between amorphous and crystalline phase } \\
\text { (average RAF content) }\end{array}$ & $\begin{array}{l}\text { - Average coupling between amorphous and crystalline phase } \\
\text { (average RAF content) }\end{array}$ \\
\hline & $\begin{array}{l}\text { Gain in barrier } \\
\text { properties }\end{array}$ & Average & Average \\
\hline
\end{tabular}


can be concluded by the comparison of sample G130_1200_37 (Fig. 3d) and M130_1200_41 (Fig. 3h). These samples have a similar RAF content and that is why they had equal gas barrier properties, even if the spherulite sizes were very different (Table 2). The importance of the RAF for the barrier properties of semicrystalline PLA can be observed by the comparison of the samples G130_20_34 and G130_1200_37, which had almost the same crystallinity degree, similar crystalline morphology and similar relaxation dynamics in the MAF. The oxygen diffusion coefficient of G130_1200_37 was more than two times higher than that of G130_20_34 and also the RAF of G130_1200_37 was about two times higher than that of G130_20_34. The low RAF of sample G130_20_34 can be explained by the hypothesis that this sample was highly nucleated before crystallization. This caused a rapid crystallization not leaving enough time for the formation of the RAF. The sample G85_1200_39 presented the highest quantity of RAF (21\%). The oxygen diffusion coefficient of this sample was almost equal to that of amorphous PLA, and the permeability gain was uniquely obtained by the decrease of oxygen solubility in the annealed sample. These results point to the importance of the RAF for the gas barrier properties of PLA. In that, they confirm essentially the hypothesis proposed by Guinault et al. [14] and allow ruling out other effects linked to crystalline morphology and structure.

A global summary of the impact of the sample morphology and amorphous phase dynamics is given in Table 4 .

We conclude that the RAF increased locally the diffusion coefficient. It is composed of insufficient decoupled tie molecules between the crystalline and the amorphous phase, which hinders the relaxation of the polymer chains and thereby increases the free volume at the crystallite/amorphous phase interface. This free volume is available for the accelerated diffusive transport of small molecules. The sample G130_20_34, which had the best barrier properties of the sample set, was particularly interesting because it showed a means for optimizing PLA barrier properties. In brief, PLA should be pre-nucleated and crystallized from the glass in the aim to obtain a high crystallinity degree very quickly. The prolongation of the annealing during a long time in the aim of obtaining a higher crystallinity is yet disadvantageous, because of the mobility of macromolecular chains in the MAF (in particular at high temperatures). This mobility can be the reason for gradual conversion of MAF into RAF with time.

\section{Conclusion}

In the present work, the impact of the crystalline structure and the amorphous phase dynamics of PLA on its oxygen barrier properties were studied. We conclude that the quantity of the rigid amorphous phase is the preponderant factor governing the oxygen diffusion coefficient. The crystalline morphology and structure (in the limit of the here used methodology of thermal annealing) and the relaxation dynamics of the mobile amorphous phase have negligible impact on the diffusion coefficient and the solubility coefficient is ruled by the crystallinity degree. We propose that the insufficient decoupling between the amorphous and the crystalline phase in PLA generates supplementary free volume at the vicinity of the crystallites. This free volume can accelerate the diffusive transport of the gas molecules and cancel out the tortuosity effect induced by the presence of crystallites. From these observations the following recommendation can be formulated: In the aim of achieving optimal gas barrier properties, PLA should be prenucleated and crystallized at a high temperature (yielding the $\alpha$ polymorph) for short time to obtain a high crystallinity degree without the formation of the rigid amorphous fraction.

\section{Acknowledgements}

The authors acknowledge the Coordenação de Aperfeiçoamento de Pessoal de Nivel Superior - CAPES for the doctorate grant $n^{\circ}$ 9712-13-5 of Samira Fernandes Nassar.

The authors acknowledge furthermore the synchrotron facility SOLEIL - Beam line SWING, proposal number 20110361 for DRX measurements and Dr. Florian Meneau for his precious technical help.

\section{References}

[1] M. Schmid, K. Dallmann, E. Bugnicourt, D. Cordoni, F. Wild, A. Lazzeri, K. Noller, Properties of whey-protein-coated films and laminates as novel recyclable food packaging materials with excellent barrier properties, Int. J. Polym. Sci. 2012 (2012) 1-7, http://dx.doi.org/10.1155/2012/562381.

[2] R. Salazar, S. Domenek, V. Ducruet, Interactions of flavoured oil in-water emulsions with polylactide, Food Chem. 148 (2014) 138-146, http:// dx.doi.org/10.1016/j.foodchem.2013.10.018.

[3] S. Saeidlou, M.A. Huneault, H. Li, C.B. Park, Poly(lactic acid) crystallization, Prog. Polym. Sci. 37 (2012) 1657-1677, http://dx.doi.org/10.1016/ j.progpolymsci.2012.07.005.

[4] A.S. Michaels, H.J. Bixler, Solubility of gases in polymers, J. Polym. Sci. L (1961) $393-412$.

[5] G. A. Colomines, S. Domenek, V. Ducruet, Guinault, Integrated process simulation and die-design in sheet metal forming, Int. J. Mater. Form. 1 (2008) 607-610, http://dx.doi.org/10.1007/s12289-008-0 3290.

[6] G. Colomines, V. Ducruet, Ć. Courgneau, A. Guinault, S. Domenek, Barrier properties of poly(lactic acid) and its morphological changes induced by aroma compound sorption, Polym. Int. 59 (2010) 818-826, http://dx.doi.org/ 10.1002/pi.2793.

[7] S. Sato, T. Nyuui, G. Matsuba, K. Nagai, Correlation between interlamellar amorphous structure and gas permeability in poly(lactic acid) films, J. Appl. Polym. Sci. 131 (2014), http://dx.doi.org/10.1002/app.40626 n/a-n/a.

[8] C. Courgneau, S. Domenek, R. Lebossé, A. Guinault, L. Avérous, V. Ducruet, Effect of crystallization on barrier properties of formulated polylactide, Polym. Int. 61 (2012) 180-189, http://dx.doi.org/10.1002/pi.3167.

[9] H. Sawada, Y. Takahashi, S. Miyata, S. Kanehashi, S. Sato, K. Nagai, Gas transport properties and crystalline structures of poly(lactic acid) membranes, Trans. Mater. Res. Soc. Jpn. 35 (2010) 241-246, http://dx.doi.org/10.14723/ tmrsj.35.241.

[10] M. Cocca, M.L. Di Lorenzo, M. Malinconico, V. Frezza, Influence of crystal polymorphism on mechanical and barrier properties of poly(l-lactic acid), Eur. Polym. J. 47 (2011) 1073-1080, http://dx.doi.org/10.1016/ j.eurpolymj.2011.02.009.

[11] N. Delpouve, A. Saiter, E. Dargent, Water barrier properties in biaxially drawn poly ( lactic acid ) films, J. Phys. Chem. B 116 (2012) 4615-4625, http:// dx.doi.org/10.1021/jp211670g.

[12] S. Kanehashi, A. Kusakabe, S. Sato, K. Nagai, Analysis of permeability; solubility and diffusivity of carbon dioxide; oxygen; and nitrogen in crystalline and liquid crystalline polymers, J. Memb. Sci. 365 (2010) 40-51, http://dx.doi.org/ 10.1016/j.memsci.2010.08.035.

[13] M. Drieskens, R. Peeters, J. Mullens, D. Franco, P. Lemstra, D. HristovaBogaerds, Structure versus properties relationship of poly(lactic acid). I. Effect of crystallinity on barrier properties, J. Polym. Sci. Part B Polym. Phys. 47 (2009) 2247-2258, http://dx.doi.org/10.1002/polb.21822.

[14] A. Guinault, C. Sollogoub, V. Ducruet, S. Domenek, Impact of crystallinity of poly(lactide) on helium and oxygen barrier properties, Eur. Polym. J. 48 (2012) 779-788, http://dx.doi.org/10.1016/j.eurpolymj.2012.01.014.

[15] K. Wasanasuk, K. Tashiro, Crystal structure and disorder in Poly(l-lactic acid) $\delta$ form ( $\alpha$ ' form) and the phase transition mechanism to the ordered $\alpha$ form, $\begin{array}{llll}\text { Polymer } & 52 & \text { (2011) 6097-6109, http://dx.doi.org/10.1016/ }\end{array}$ j.polymer.2011.10.046.

[16] K. Wasanasuk, K. Tashiro, Structural regularization in the crystallization process from the glass or melt of poly(l-lactic acid) viewed from the temperature-dependent and time-resolved measurements of FTIR and wideangle/small-angle X-ray scatterings, Macromolecules 44 (2011) 9650-9660, http://dx.doi.org/10.1021/ma2017666.

[17] T. Kawai, N. Rahman, G. Matsuba, K. Nishida, T. Kanaya, M. Nakano, H. Okamoto, J. Kawada, A. Usuki, N. Honma, K. Nakajima, M. Matsuda, Crystallization and melting behavior of poly (L-lactic acid), Macromolecules 40 (2007) 9463-9469.

[18] H. Bai, C. Huang, H. Xiu, Q. Zhang, H. Deng, K. Wang, F. Chen, Q. Fu, Significantly improving oxygen barrier properties of polylactide via constructing parallel-aligned shish-kebab-like crystals with well-interlocked boundaries, Biomacromolecules 15 (2014) 1507-1514, http://dx.doi.org/10.1021/ bm500167u.

[19] N. Delpouve, A. Saiter, J.F. Mano, E. Dargent, Cooperative rearranging region size in semi-crystalline poly(L-lactic acid), Polymer 49 (2008) 3130-3135, http://dx.doi.org/10.1016/j.polymer.2008.04.045.

[20] N. Delpouve, M. Arnoult, A. Saiter, E. Dargent, J. Saiter, Evidence of two mobile 
amorphous phases in semicrystalline polylactide observed from calorimetric investigations, Polym. Eng. Sci. 54 (2014) 1144-1150, http://dx.doi.org/ 10.1002/pen.23657.

[21] M. Arnoult, E. Dargent, J.F. Mano, Mobile amorphous phase fragility in semicrystalline polymers: comparison of PET and PLLA, Polym. Guildf. 48 (2007) 1012-1019, http://dx.doi.org/10.1016/j.polymer.2006.12.053.

[22] E. Zuza, J.M. Ugartemendia, A. Lopez, E. Meaurio, A. Lejardi, J.R. Sarasua, Glass transition behavior and dynamic fragility in polylactides containing mobile and rigid amorphous fractions, Polymer 49 (2008) 4427-4432, http:// dx.doi.org/10.1016/j.polymer.2008.08.012.

[23] B. Wunderlich, Reversible crystallization and the rigid-amorphous phase in semicrystalline macromolecules, Prog. Polym. Sci. 28 (2003) 383-450, http:// dx.doi.org/10.1016/S0079-6700(02)00085-0.

[24] J. Del Rıó, A. Etxeberria, N.L. Lopez-Rodrıuez, E. Lizundia, J.R. Sarasua, A PALS contribution to the supramolecular structure of poly(l-lactide), Macromolecules 43 (2010) 4698-4707, http://dx.doi.org/10.1021/ma902247y.

[25] N. Delpouve, L. Delbreilh, G. Stoclet, A. Saiter, E. Dargent, Structural dependence of the molecular mobility in the amorphous fractions of polylactide, Macromolecules 47 (2014) 5186-5197, http://dx.doi.org/10.1021/ ma500839p.

[26] A. Saiter, N. Delpouve, E. Dargent, W. Oberhauser, L. Conzatti, F. Cicogna, E. Passaglia, Probing the chain segment mobility at the interface of semicrystalline polylactide/clay nanocomposites, Eur. Polym. J. 78 (2016) 274-289, http://dx.doi.org/10.1016/j.eurpolymj.2016.03.040.

[27] J.M. Hutchinson, Studying the glass transition by DSC and TMDSC, J. Therm. Anal. Calorim. 72 (2003) 619-629, http://dx.doi.org/10.1023/A:1024542103314.

[28] B.E.W. Fischer, H.J. Sterzel, G. Wegner, Investigation of the structure of solution grown crystals of lactide copolymers by means of chemical reactions by means of chemical reactions, Kolloid-Z. U. Z. Polym. 251 (1973) 980-990.

[29] M.C. Righetti, M. Gazzano, M.L. Di Lorenzo, R. Androsch, Enthalpy of melting of $\alpha^{\prime}$ - and $\alpha$-crystals of poly(L-lactic acid), Eur. Polym. J. 70 (2015) 215-220, http://dx.doi.org/10.1016/j.eurpolymj.2015.07.024.

[30] N. Delpouve, a. Saiter, E. Dargent, Cooperativity length evolution during crystallization of poly(lactic acid), Eur. Polym. J. 47 (2011) 2414-2423, http:/ dx.doi.org/10.1016/j.eurpolymj.2011.09.027.

[31] T. Funaki, A. Kondo, K. Kanai, Analysis of contributing factors to production of highly transparent isotactic polypropylene extrusion sheets. Part 2, Polym. Eng. Sci. 51 (2011) 1068-1077.

[32] T. Funaki, A. Kanai, T. Saito, Y. Yamada, Analysis of contributing factors to production of highly transparent isotactic polypropylene extrusion sheets, Part I, Polym. Eng. Sci. 50 (2010) 2356-2365.

[33] M. Pluta, A. Galeski, Crystalline and supermolecular structure of polylactide in relation to the crystallization method, J. Appl. Polym. Sci. 86 (2002) 1386-1395, http://dx.doi.org/10.1002/app.11280.

[34] P. Pan, B. Zhu, W. Kai, T. Dong, Y. Inoue, Effect of crystallization temperature on crystal modifications and crystallization kinetics of poly(L-lactide), J. Appl. Polym. Sci. 107 (2008) 54-62, http://dx.doi.org/10.1002/app.27102.

[35] M. Yasuniwa, S. Tsubakihara, K. Iura, Y. Ono, Y. Dan, K. Takahashi, Crystallization behavior of poly(l-lactic acid), Polymer 47 (2006) 7554-7563, http:// dx.doi.org/10.1016/j.polymer.2006.08.054.

[36] X.J. Li, G.J. Zhong, Z.M. Li, Non-isothermal crystallization of poly(L-lactide) (PLLA) under quiescent and steady shear conditions, Chin. J. Polym. Sci. 28 (2010) 357-366, http://dx.doi.org/10.1007/s10118-010-9015-z.

[37] M.L. Di Lorenzo, Determination of spherulite growth rates of poly(l-lactic acid) using combined isothermal and non-isothermal procedures, Polymer 42 (2001) 9441-9446. http://dx.doi.org/10.1016/S0032-3861(01)00499-2.

[38] R. Androsch, M.L. Di Lorenzo, C. Schick, Crystal nucleation in random 1/dlactide copolymers, Eur. Polym. J. 75 (2016) 474-485, http://dx.doi.org 10.1016/j.eurpolymj.2016.01.020.

[39] R. Androsch, H.M.N. Iqbal, C. Schick, Non-isothermal crystal nucleation of poly (l-lactic acid), Polymer 81 (2015) 151-158, http://dx.doi.org/10.1016/ j.polymer.2015.11.006.

[40] R.T. MacDonald, R.A. Gross, S.P. McCarthy, Enzymatic degradability of poly(lactide): effects of chain stereochemistry and material crystallinity, Macromolecules 29 (1996) 7356-7361, http://dx.doi.org/10.1021/ma960513j.

[41] H. Tsuji, S. Miyauchi, Enzymatic hydrolysis of free and restricted amorphous regions in poly(L-lactide) films with different crystallinities and a fixed crystalline thickness, Polymer 42 (2001) 4463-4467, http://dx.doi.org/ 10.1016/S0032-3861(00)00792-8.

[42] S. Samarajeewa, R. Shrestha, Y. Li, K.L. Wooley, Degradability of poly(lactic acid)-containing nanoparticles: enzymatic access through a cross-linked shel barrier, J. Am. Chem. Soc. 134 (2012) 1235-1242, http://dx.doi.org/10.1021/ ja2095602.

[43] M.L. Di Lorenzo, M. Cocca, M. Malinconico, Crystal polymorphism of poly(llactic acid) and its influence on thermal properties, Thermochim. Acta 522 (2011) 110-117, http://dx.doi.org/10.1016/j.tca.2010.12.027.

[44] S. Iannace, L. Nicolais, Isothermal crystallization and chain mobility of poly ( L -lactide ), J. Appl. Polym. Sci. (1997) 911-919.

[45] M. Pyda, R.C. Bopp, B. Wunderlich, Heat capacity of poly(lactic acid), J. Chem. Thermodyn. 36 (2004) 731-742, http://dx.doi.org/10.1016/j.jct.2004.05.003.

[46] M. Kanchanasopa, J. Runt, Broadband dielectric investigation of amorphous and semicrystalline l-lactide/meso-lactide copolymers, Macromolecules 37 (2004) 863-871. http://pubs.acs.org/doi/abs/10.1021/ma035597s/npapers3:// publication/doi/10.1021/ma035597s.

[47] M.C. Righetti, E. Tombari, Crystalline, mobile amorphous and rigid amorphous fractions in poly(L-lactic acid) by TMDSC, Thermochim. Acta 522 (2011) 118-127, http://dx.doi.org/10.1016/j.tca.2010.12.024.

[48] G. Adam, J.H. Gibbs, On the temperature dependence of cooperative relaxation properties in glass-forming liquids, J. Chem. Phys. 43 (1965) 139-146, http:// dx.doi.org/10.1063/1.1696442.

49] E. Hempel, G. Hempel, a. Hensel, C. Schick, E. Donth, Characteristic length of dynamic glass transition near $\mathrm{Tg}$ for a wide assortment of glass-forming substances, J. Phys. Chem. B 104 (2000) 2460-2466, http://dx.doi.org/ 10.1021/jp991153f.

[50] E. Donth, The size of cooperatively rearranging regions at the glass transition, J. Non. Cryst. Solids 53 (1982) 325-330, http://dx.doi.org/10.1016/00223093(82)90089-8.

[51] A. Saiter, N. Delpouve, E. Dargent, J.M. Saiter, Cooperative rearranging region size determination by temperature modulated DSC in semi-crystalline poly(1lactide acid), Eur. Polym. J. 43 (2007) 4675-4682, http://dx.doi.org/10.1016/ j.eurpolymj.2007.07.039.

[52] C. Lixon, N. Delpouve, a. Saiter, E. Dargent, Y. Grohens, Evidence of cooperative rearranging region size anisotropy for drawn PET, Eur. Polym. J. 44 (2008) 3377-3384, http://dx.doi.org/10.1016/j.eurpolymj.2008.08.001.

[53] N. Delpouve, C. Lixon, a. Saiter, E. Dargent, J. Grenet, Amorphous phase dynamics at the glass transition in drawn semi-crystalline polyester: DDDMA and TMDSC comparative studies, J. Therm. Anal. Calorim. 97 (2009) 541-546 http://dx.doi.org/10.1007/s10973-008-9670-2. 